\title{
SCREENING OF ACTINOMYCETES ISOLATED FROM NATURAL ECOSYSTEM (PERIYAR TIGER RESERVE, KERALA) FOR LIPASE INHIBITORY ACTIVITIES
}

\author{
DIKSHA KUMARI, DEEPU SURENDRAN, ESLIN KHYMDEIT, VENKATA KRISHNA BAYINENI*
}

Department of Microbiology, Indian Academy Degree College - Autonomous, Centre for Research and Post Graduate Studies, Bengaluru, Karnataka, India. Email: krishnabayineni@gmail.com

Received: 02 July 2019, Revised and Accepted: 04 September 2019

\section{ABSTRACT}

Objectives: The present study was undertaken to screen pancreatic lipase inhibitory activity of crude extracts of actinomycetes species isolated from the soil sediments of Periyar Tiger Reserve, Kerala. The identified lipase inhibitory activity was partially purified, and the selected isolate was identified by $16 \mathrm{~S}$ rRNA sequencing.

Methods: The preliminary screening for the extracellular lipase inhibitory activities of actinomycetes isolates was performed by inoculating the culture to the test tubes containing inoculation media in submerged condition. The lipase inhibitory activities were again evaluated based on secondary screening on the production media and the strain which produced consistent highest lipase inhibitory activity was selected for further studies. The crude extract from the selected strain was subjected to solvent extraction and partially purified by plain silica gel column (mesh size 100-200 $\mu \mathrm{m}$; column $300 \mathrm{~mm} \times 18 \mathrm{~mm}$ ) and eluted with different solvents in the increasing order of polarity and all the solvent fractions were checked for lipase inhibitory activity.

Results: Based on the secondary screening on the production of media, DDE6 strain showed highest lipase inhibitory activity (96.2\%) and was selected for further studies. The dichloromethane extract showed the highest lipase inhibitory activity (96.38\%) when compared to other solvents. The partial 16S rRNA sequence analysis of DDE6 isolate confirmed the strain as Curtobacterium oceanosedimentum.

Conclusion: Many research publications have reported the isolation of Curtobacterium species and its type strains. However, this is the first time to report its potential to produce lipase inhibitor metabolite under submerged fermentation conditions. Further, studies are needed to be conducted to characterize the active principle of lipase inhibition as well as to elucidate the structure of the extracted compound.

Keywords: Obesity, Lipase inhibitor, Actinomycetes, Para-nitro phenylbutyrate.

(C) 2019 The Authors. Published by Innovare Academic Sciences Pvt Ltd. This is an open access article under the CC BY license (http://creativecommons. org/licenses/by/4. 0/) DOI: http://dx.doi.org/10.22159/ajpcr.2019.v12i10.34744

\section{INTRODUCTION}

Obesity is an abnormal increase in body fat and caused due to higher basal metabolism, lower fat oxidation rate, lower physical activity, and increased insulin sensitivity. Lipases (E. C. 3.1.1.3) are the enzymes that catalyze the hydrolysis of triacylglycerols to glycerol and fatty acids (FAs), and these enzymes play an important role in the metabolism of lipids. Obesity is a lipid metabolism disorder and ranks fifth for death caused worldwide. Absorption of dietary lipids is targeted for developing anti-obesity compounds [1,2]. Compounds belonging to certain classes of natural products are broadly studied for antiobesity activities, such compound includes polyphenols, terpenoids, polysaccharides, and glycosides. The microbial source produces lipophilic compounds which are active against lipid absorption. The lipophilic compound selectively limits the absorption of dietary fat and thus considered as a therapeutic agent for the treatment of obesity as well as hyperlipidemia [3]. Actinomycetes are reported to produce richest sources of secondary metabolites which are used as antibiotics, therapeutic agents, inhibitory compounds, etc. $[4,5]$. The important genera of actinomycetes which are known to produce various classes of secondary metabolites are Actinomycetes, Nocardia, Micromonospora, and Thermomonospora [1]. The currently available anti-obesity drugs show side effects. Sibutramine belongs to the class phenethylamine which is approved for long-term treatment of obesity in adults. Common side effects include dry mouth, hypertension, palpitation, and insomnia [6]. Rimonabant blocks cannabinoid-1 receptor which is responsible for stimulating increase in appetite, thus reduces food intake. Common side effect includes dizziness, vomiting, and diarrhea [7]. Many pancreatic lipase inhibitors are reported from the plant sources, and they can be classified into saponins, phenols, terpenes, glycosides, alkaloids, carotenoids, and polysaccharides. Plant pancreatic lipase inhibitors are reported to show the anti-obesity effects in the animal models. However, there is no plant inhibitor in clinical use [8-10]. Orlistat is a potent inhibitor of pancreatic lipase and is the first commercially available drug approved by FDA. Orlistat inhibits gastric and pancreatic lipases and thus prevents the absorption of fats from food intake, and as a result, triglycerides are not hydrolyzed into free FAs [6]. Common side effects include liquid stool, flatulence, abdominal cramps, inability to control bowel movements, nausea, vomiting, diarrhea, rectal pain, weakness, dark urine, loss of appetite, and jaundice [1]. Other lipase inhibitory compounds from microbial sources are panclicins, tetrahydrolipstatin, valilactone, cyclipostins, shamstatin, ebelactone, and esterastin. All these inhibitory compounds are produced from actinomycetes species. However, their uses are restricted due to side effects $[11,12]$. Hence, there is a need for the production novel metabolites from the available natural sources, thus leading to the development of powerful lipase inhibitors.

\section{METHODS}

Isolation and identification of actinomycete isolate

The actinomycete species of this study were isolated from a soil sample of Western Ghats: Periyar Tiger Reserve, Kumily Thekkady Road, Thekkady, Kumily, Kerala (9.588314, 77.180068). The soil sample was collected from a depth of $5 \mathrm{~cm}$ in sterile container. The soil sample was pre-treated in hot air oven at a temperature of $40-50^{\circ} \mathrm{C}$ for a week. The pre-treated soil samples were serially diluted and plated on starch casein agar (SCA) (HiMedia, Mumbai). The inoculated 
plates were incubated at $30^{\circ} \mathrm{C}$ for a week aerobically. The isolates were sub-cultured on fresh medium and identified to genus level based on colony morphology and Gram's staining. The isolates were maintained on SCA slant.

\section{Media and culturing of actinomycetes}

The inoculation and production media were prepared using deionized water, and the $\mathrm{pH}$ was adjusted to seven and sterilized for $20 \mathrm{~min}$ at $15 \mathrm{lbs}$ and $121^{\circ} \mathrm{C}$. The sub-cultured slants were used to carry out the experiments. The artificial seawater is used as a diluent. The composition of these media is given in Tables 1-3. The media were supplemented with fluconazole $75 \mu \mathrm{g} / \mathrm{ml}$ and rifampicin $2.5 \mu \mathrm{g} / \mathrm{ml}$ to eliminate or minimize fungal and bacterial growth. This medium has starch as the complex carbohydrate source and casein as a nitrogen source.

\section{Growth of isolates in the production media}

In the fermentation process, the choice of the most effective fermentation media is very important for high yield of product. A good quality fermentation media is very important as it provides nutrients and energy for growth of micro-organisms. These media provide substrate for product synthesis in a fermenter. The production media were provided with all the simple and complex nutrition. Organisms were inoculated into the production media for optimal growth of the organisms. At different days of the growth cycle, the organisms will start to produce primary and secondary metabolites. Twenty isolates were inoculated to $20 \mathrm{ml}$ production media tubes and incubated at $30^{\circ} \mathrm{C}$ and the culture was harvested on $10^{\text {th }}$ day of inoculation to check the lipase inhibitory activity.

\section{Lipase inhibition assay}

Lipase inhibitory activity in the extracts was estimated by adopting the method described below [13]. Porcine pancreatic lipase (20 units) was pre-incubated with the $400 \mu \mathrm{l}$ of appropriately diluted extract (diluted with $2.5 \mathrm{mM}$ Tris- $\mathrm{HCl}$ buffer containing $2.5 \mathrm{mM} \mathrm{NaCl}, \mathrm{pH} 7.4$ ) for $60 \mathrm{~min}$ at $37^{\circ} \mathrm{C}$. Then, $2 \mathrm{ml}$ of the substrate, para-nitro phenylbutyrate (PNPB) $(200 \mu \mathrm{M})$ was added, and the residual lipase activity (\%) was

\section{Table 1: Composition of inoculation media}

\begin{tabular}{ll}
\hline Ingredients & g/l \\
\hline Soybean meal & 10 \\
Corn steep liquor & 10 \\
Glucose $_{\mathrm{CaCO}_{3}}$ & 10 \\
\hline
\end{tabular}

Table 2: Composition of production media

\begin{tabular}{ll}
\hline Ingredients & g/l \\
\hline Soluble starch & 10 \\
Soybean meal & 20 \\
Yeast extract & 2 \\
Glucose $_{\mathrm{CaCO}}$ & 10 \\
$\mathrm{NaCl}$ & 3 \\
$\mathrm{CaSein}_{\text {FeSO }} \cdot \mathrm{H}_{2} \mathrm{O}$ & 5 \\
\hline
\end{tabular}

Table 3: Seawater composition

\begin{tabular}{ll}
\hline Ingredients & g/l \\
\hline Chloride & 19.35 \\
Sodium & 10.76 \\
Magnesium & 1.29 \\
Sulfate & 2.71 \\
Calcium & 0.41 \\
Potassium & 0.39 \\
\hline
\end{tabular}

determined by carrying out the reaction at $37^{\circ} \mathrm{C}$ for $30 \mathrm{~min}$. Lipase will convert the substrate PNPB into para-nitrophenol. The released p-nitrophenol was quantified spectrophotometrically (Shimadzu, ultraviolet [UV] 1800) at $410 \mathrm{~nm}$ by plotting the standard graph with different concentrations of p-nitrophenol (1-10 $\mu \mathrm{g} / \mathrm{ml})$. The activity of lipase was determined as the $\mu$ moles of p-nitrophenol released per min. Orlistat was used as a positive control, and the percentage of enzyme inhibited was calculated by referring to the control that has no culture extract.

Purification of lipase inhibitor by bioactivity guided fractionization Around 2 l of DDE6 culture was grown in the production medium at $30^{\circ} \mathrm{C}$ at $200 \mathrm{rpm}$ for 10 days. The total culture supernatant was extracted with equal amounts of ethyl acetate for $2 \mathrm{~h}$ at $150 \mathrm{rpm}$, and ethyl acetate was separated from the crude extract and was evaporated at $40^{\circ} \mathrm{C}$ using rotary evaporator. The concentrate obtained was collected with dimethyl sulfoxide (DMSO) and run with silica gel. The clear sample was loaded on the top of the plain silica gel column (mesh size 100$200 \mu \mathrm{m}$; column $300 \mathrm{~mm} \times 18 \mathrm{~mm}$ ) and eluted with different solvents (hexane, carbon tetrachloride, dichloromethane, chloroform, methanol, diethylamine, DMSO, and water) in the increasing order of polarity at the flow rate of $1 \mathrm{ml} / \mathrm{min}$. All the solvent fractions were checked for lipase inhibitory activity.

\section{Sequencing of the complete genome of the selected strains}

The selected strain DDE6 was sent to a company named as barcode biosciences for microbial identification using 16S rRNA based molecular method and phylogenetic analysis. Phylogenetic trees represent hypotheses about the evolutionary relationships among a group of organisms. The branching of the phylogenetic tree reflects how species or other groups evolved from a series of common ancestors. In phylogenetic trees, those species that have recent common ancestor are more related while those which have less recent common ancestor are less related.

\section{RESULTS AND DISCUSSION}

\section{Morphological characterization of the isolates}

A total number of 20 actinomycetes strains were isolated from the selected soil samples. The isolates were identified on the basis of microscopic and morphological characteristics. The isolated colonies were powdery in nature. The colonies showed grayish black, white color with shiny appearance. The isolates were Gram positive in nature (Fig. 1). On microscopic analysis, it showed the arrangement of spores, filamentous bacteria with well-developed vegetative hyphae with branches (Fig. 1). The total 20 isolates were suspected to be actinomycetes and are isolated and labeled as DDE1-DDE20. The isolated strains are further screened for lipase inhibitory activity.

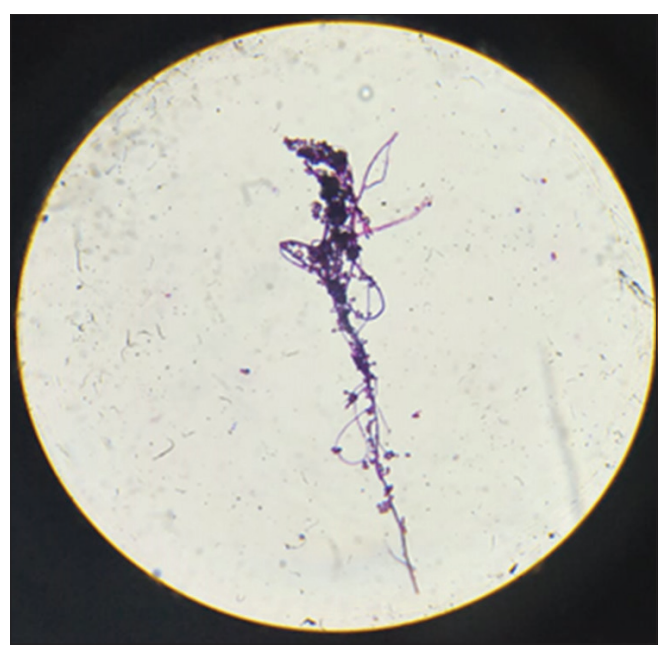

Fig. 1: Microscopic view of DDE6 isolate (spore arrangement) 
Table 4: Lipase inhibitory activities of the isolated microbial extracts by spectrophotometry

\begin{tabular}{|c|c|c|c|}
\hline \multicolumn{2}{|l|}{ Test 1} & \multicolumn{2}{|l|}{ Test 2} \\
\hline $\begin{array}{l}\text { Crude sample } \\
\text { from the isolates }\end{array}$ & $\begin{array}{l}\text { Percentage of lipase inhibition } \\
\text { before adjusting the } \mathrm{pH}(\text { Mean } \pm \mathrm{SD})\end{array}$ & $\begin{array}{l}\text { pH of original crude } \\
\text { extract }\end{array}$ & $\begin{array}{l}\text { Lipase inhibition (\%) after } \\
\text { adjusting the pH to } 7.7 \text { (Mean } \pm \text { SD) }\end{array}$ \\
\hline DDE1 & $22.85 \pm 0.82$ & 7 & $26.3 \pm 0.95$ \\
\hline DDE2 & $10.25 \pm 0.26$ & 5.5 & $20.2 \pm 0.56$ \\
\hline DDE3 & $63.41 \pm 1.47$ & 6 & $31.2 \pm 0.63$ \\
\hline DDE4 & $53.65 \pm 1.63$ & 6 & $15.92 \pm 0.26$ \\
\hline DDE5 & $5.60 \pm 0.02$ & 7 & $2.7 \pm 0.12$ \\
\hline DDE6 & $96.6 \pm 2.01$ & 6 & $96.2 \pm 1.36$ \\
\hline DDE7 & $30.6 \pm 0.65$ & 7 & $23.0 \pm 0.35$ \\
\hline DDE8 & $80.48 \pm 2.25$ & 5 & $14.29 \pm 0.21$ \\
\hline DDE9 & $23.73 \pm 1.16$ & 5 & 0 \\
\hline DDE10 & $92.68 \pm 1.89$ & 7 & $67.4 \pm 2.31$ \\
\hline DDE11 & $49.91 \pm 0.87$ & 6 & $29.6 \pm 0.96$ \\
\hline DDE12 & $1.78 \pm 0.1$ & 7 & $4.1 \pm 0.12$ \\
\hline DDE13 & $54.30 \pm 0.65$ & 7 & $75.78 \pm 1.585$ \\
\hline DDE14 & $13.49 \pm 0.15$ & 6 & $6.93 \pm 0.2$ \\
\hline DDE15 & $6.17 \pm 0.36$ & 6 & $2.6 \pm 0.11$ \\
\hline DDE16 & $26.75 \pm 1.23$ & 7 & $12.8 \pm 0.36$ \\
\hline DDE17 & $98.37 \pm 2.36$ & 6 & $67.4 \pm 2.11$ \\
\hline DDE18 & $6.75 \pm 0.35$ & 6.5 & $7.8 \pm 0.36$ \\
\hline DDE19 & $11.05 \pm 0.41$ & 8 & $46.4 \pm 0.45$ \\
\hline DDE20 & 0 & 7 & 0 \\
\hline
\end{tabular}

SD: Standard deviation

\section{Screening for lipase inhibitory activity}

Preliminary screening for lipase inhibitory metabolite producing the ability of the isolates was tested by checking the crude extracts of the isolates. The isolates were inoculated to inoculation media and then to production media and incubated at $30^{\circ} \mathrm{C}$ for 10 days to permit growth and secondary metabolite production. Pancreatic lipase inhibitory activity of extract was tested against pancreatic lipase extracted from the chicken pancreas. The inhibition of lipase activity (\%) was calculated using the formula:

$$
\text { Lipase inhibition }=\frac{\mathrm{B}}{\mathrm{A}} \times 100
$$

Where A is lipase activity, B is activity of lipase when incubated with the extract.

The result of screening for lipase and lipase inhibitory activities of the isolates by biochemical assay method is depicted in Table 4 . The result was recorded, as the decrease in lipase activity (optical density at $410 \mathrm{~nm}$ ) in the presence of crude extract. It was observed that the activity of lipase was affected when incubated with the crude extracts. The inhibition of lipase activity was found to be more in sample DDE6 (96.2) (Table 4) although 50-80\% inhibition was observed in few other samples.

In addition, during the spectrophotometric assay, if the sample $\mathrm{pH}$ is not adjusted toward neutral, the pancreatic lipase will lose its activity and assay gives false positives (Table 4). The false positives were noticed after adjusting the $\mathrm{pH}$ of the crude sample to 7.7. The samples which showed potent lipase inhibition (DDE6, DDE10, DDE13, and DDE17) were selected and grown again in production media to confirm their production of lipase inhibitor and the results were reproducing (data not shown). The DDE6 isolate with $96.2 \%$ inhibition was selected for further studies.

Time course study on the submerged production of lipase inhibitor Time course study was done in the production media for the extracellular production of lipase inhibitor from the DDE6 isolate, and significant productivity was observed on $6^{\text {th }}$ day of fermentation and reached maximum at $7^{\text {th }}$ day, and after that there was no increase after that (Fig. 2).

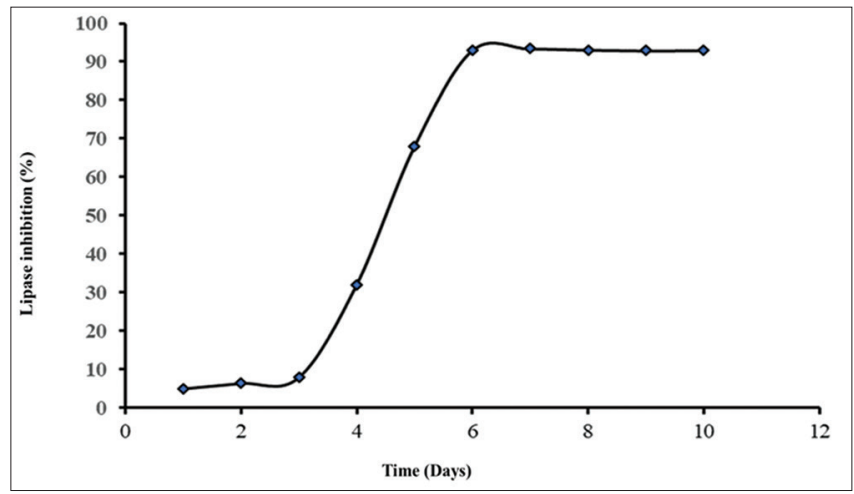

Fig. 2: Time course study on the productivity of the lipase inhibitor by DDE6 isolates in the submerged culture using production medium

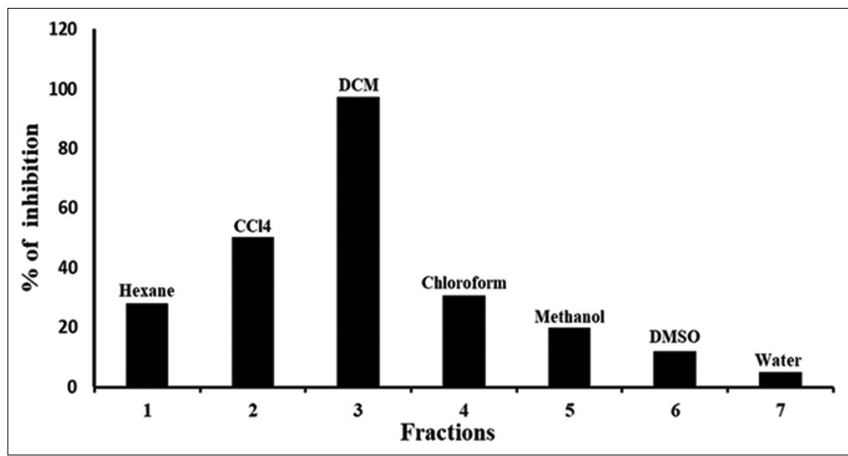

Fig. 3: Graph showing the elution of lipase inhibitory activity by different solvents from the extract bound to silica gel

\section{Bioactivity-guided purification}

The bioactivity-guided purification procedure was described in the chapter, materials, and methods. During the bioactivity-guided fractionation of ethyl acetate crude extract on silica gel, diethyl ether fraction retained the maximum lipase inhibitory activity. The lipase inhibition (\%) was checked in UV-Vis spectrophotometer (UV 1700, 


\begin{tabular}{|l|c|c|c|c|c|c|}
\hline \multicolumn{1}{|c|}{ Description } & $\begin{array}{c}\text { Max } \\
\text { Score }\end{array}$ & $\begin{array}{c}\text { Total } \\
\text { Score }\end{array}$ & $\begin{array}{c}\text { Query } \\
\text { Cover }\end{array}$ & $\begin{array}{c}\text { E } \\
\text { value }\end{array}$ & $\begin{array}{c}\text { Per. } \\
\text { Ident }\end{array}$ & Accession \\
\hline $\begin{array}{l}\text { Curtobacterium oceanosedimentum strain } \\
\text { S52_MA1R }\end{array}$ & 1906 & 1906 & $100 \%$ & 0 & $99.90 \%$ & MK883133.1 \\
\hline Curtobacterium luteum strain IAE64 & 1906 & 1906 & $100 \%$ & 0 & $99.90 \%$ & MK415011.1 \\
\hline $\begin{array}{l}\text { Curtobacterium oceanosedimentum strain } \\
\text { IAES6 }\end{array}$ & 1906 & 1906 & $100 \%$ & 0 & $99.90 \%$ & MK415002.1 \\
\hline $\begin{array}{l}\text { Curtobacterium sp. strain IAE256 } \\
\text { Curtobacterium citreum strain IAE192 }\end{array}$ & 1906 & 1906 & $100 \%$ & 0 & $99.90 \%$ & MK414963.1 \\
\hline Curtobacterium sp. strain IAE157 & 1906 & 1906 & $100 \%$ & 0 & $99.90 \%$ & MK414853.1 \\
\hline Curtobacterium sp. strain IAE154 & 1906 & 1906 & $100 \%$ & 0 & $99.90 \%$ & MK414850.1 \\
\hline Curtobacterium sp. strain H4 & 1906 & 1906 & $100 \%$ & 0 & $99.90 \%$ & MK704290.1 \\
\hline $\begin{array}{l}\text { Curtobacterium oceanosedimentum strain } \\
\text { CD20 }\end{array}$ & 1906 & 1906 & $100 \%$ & 0 & $99.90 \%$ & MK618608.1 \\
\hline \begin{tabular}{l} 
Curtobacterium luteum strain CB13 \\
\hline
\end{tabular} & 1906 & 1906 & $100 \%$ & 0 & $99.90 \%$ & MK618607.1 \\
\hline
\end{tabular}

Fig. 4: Sequences producing significant alignments of DDE6

Shimadzu) at $420 \mathrm{~nm}$ for different solvents (hexane $27.98 \%$, carbon tetrachloride $50.37 \%$, dichloromethane $96.38 \%$, chloroform $30.59 \%$, methanol 19.78\%, DMSO 12.31\%, and water 5.22\%) (Fig. 3). Hence, among all those fractions dichloromethane has shown the highest percentage for lipase inhibitor with $97.38 \%$. A graph was plotted by percentage of inhibition on Y-axis and number of fractions on X-axis, after a graph has been plotted; dichloromethane was showed the highest peak. Hence, dichloromethane can dissolve compounds better, but it will take longer time to run through the silica.

The selected strain which showed highest lipase inhibitory activity (DDE6) was sent for microbial identification using 16S rRNA based molecular method in the company "barcode biosciences." Phylogenetic analysis of the samples was performed which represents evolutionary relationships among organisms. The pattern of branching in a phylogenetic tree reflects how species or other groups evolved from a series of common ancestors. Genomic DNA of the DDE6 strain was isolated, and 16S rRNA gene was polymerase chain reaction amplified with specific forward and reverse primers. The BLAST search analysis revealed $100 \%$ homology with the strain Curtobacterium oceanosedimentum (Fig. 4).

\section{DISCUSSION}

Actinomycetes are very well known and successfully exploited as a source of secondary metabolites. Out of the approximately 10,000 known antibiotics, $45-55 \%$ are produced by streptomycetes. The species of actinomycetes were known to produce various compounds that have different biomedical applications. Lipase inhibitors such as lipstatin [14,15], panclicins A-E, ebelactones A and B, valilactone [11], esterastin, cyclipostins, (E)-4-aminostyryl acetate [2], streptolysin [12], $\varepsilon$-poly-L-lysine, and shamistatin [16] were reported from actinomycetes species. In the present study, 20 actinomycetes strains were isolated from different parts of Periyar Tiger Reserve. All the isolates were assessed for their lipase inhibitory by pour plate technique on SCA. Morphological characters of the isolates were studied based on the microscopic appearance. Actinomycetes isolates were screened for the production of extracellular lipase inhibition. Preliminary screening for the extracellular activities of actinomycetes isolates was performed by inoculating the culture to the test tubes containing inoculation media in submerged condition. The active form of five isolated strains showed potential lipase inhibitory activity, and ten isolates showed lipase activity. Based on the secondary screening on production media, DDE6 strain which showed highest lipase inhibitory activity was selected for further studies. The crude extract from the active strain DDE6 was subjected to solvent extraction and partially purified by plain silica gel column (mesh size 100-200 $\mu \mathrm{m}$; column $300 \mathrm{~mm} \times 18 \mathrm{~mm}$ ) and eluted with different solvents in the increasing order of polarity and all the solvent fractions were checked for lipase inhibitory activity. Dichloromethane extract showed highest lipase inhibitory activity when compared to other solvents. The partial 16S rRNA sequence analysis of DDE6 confirmed the strain as $C$. oceanosedimentum. Many research publications have reported the isolation of C. oceanosedimentum [17] species and its type strains. However, its potential to produce lipase inhibitor metabolite under submerged fermentation conditions has not been reported. This is the first time to report $C$. oceanosedimentum isolate which could produce lipase inhibitor compound from Periyar Tiger Reserve, Kerala, India. Previous reports also revealed that actinomycetes are one of the known lipstatin producers. The activity of the 20 strains varied from isolate to isolate depending on the growth and physical condition of the isolates. This difference may be due to the nature of the sample from which they are isolated.

The lipase inhibitory activity from the isolated culture DDE6 showed potent lipase inhibitory activity (96.2\%) on pancreatic lipase, which can be further purified to study the kinetic properties of the action of the drug molecule. Chemical modification of this compound might improve its potency further. Nevertheless, it can be still explored for treating obesity. However, animal studies need to be done to place it under clinical trials. Furthermore, it can be economically produced in the solid-state fermentation which will benefit the biotech and pharma sectors during the production, if it is placed under clinical trials and approved for treating obesity. Further studies are need to be conducted to characterize the active principle of lipase inhibition as well as to elucidate the structure of the extracted compound. Overall, the characteristics of the selected strains were similar to most of the reported actinomycetes species. Further research is required to optimize the fermentation and downstream processing conditions for the economic production of the compound.

\section{CONCLUSION}

The genus actinomycetes are the largest producer of bioactive compounds, and it remains important to discover new leader compounds from actinomycetes for drug development. In this context, the present study highlighted the pancreatic lipase inhibitory potential of crude extracts of the actinomycetes species isolated from the Periyar Tiger Reserve area, Kerala. The selected actinomycete DDE6 
(C. oceanosedimentum) in the present study showed excellent activity of lipase inhibition. This isolate may be effectively used in large scale production for commercial, industrial, and pharmaceutical applications in the coming future. The metabolites of actinomycetes from Periyar Tiger Reserve area of Kerala may prove to be useful.

\section{ACKNOWLEDGMENTS}

The authors would like to thank Dr. Venkata Krishna B of the Department of Microbiology, Indian Academy Degree College - Autonomous for providing continuous guidance. The authors are also thankful to the Department of Microbiology, Indian Academy Degree College Autonomous for providing necessary laboratory facilities to carry out this work and encouragement.

\section{AUTHORS' CONTRIBUTIONS}

The authors declare that the manuscript is not submitted or being considered to another journal in part of full for publication. All authors contributed equally to the paper.

\section{CONFLICTS OF INTEREST}

The authors declare that they have no conflicts of interest.

\section{REFERENCES}

1. Lunagariya NA, Patel NK, Jagtap SC, Bhutani KK. Inhibitors of pancreatic lipase: State of the art and clinical perspectives. EXCLI J 2014;13:897-921.

2. Tokdar P, Ranadive P, Mascarenhas M, Patil M, George S. Anew pancreatic lipase inhibitor produced by streptomyces sp. MTCC 2011;5219:7-10.

3. Rodgers RJ, Tschöp MH, Wilding JP. Anti-obesity drugs: Past, present and future. Dis Model Mech 2012;5:621-6.

4. Berdy J. The discovery of new bioactive microbial metabolites: Screening and identification. Prog Ind Microbiol 1989;27:3-27.

5. Elangbam CS. Review paper: Current strategies in the development of anti-obesity drugs and their safety concerns. Vet Pathol 2009;46:10-24.

6. Kaila B, Raman M. Obesity: A review of pathogenesis and management strategies. Can J Gastroenterol 2008;22:61-8.

7. Singh G, Suresh S, Bayineni VK, Kadeppagari RK. Lipase inhibitors from plants and their medical applications. Int J Pharm Sci Res 2015;7:1-5.

8. Hidayah N, Adnyana KI, Fisheri N, Setiawan F. Antiobesity activitity of water fractions extract of tamarind (Tamarindus indica L.) in high carbohydrate diet induced male Wistar rats. Asian J Pharm Clin Res 2018;11:200-5.

9. Lai HY, Ong SL, Rao NK. In vitro lipase inhibitory effect of thirty two selected plants in Malaysia. Asian J Pharm Clin Res 2014;7:19-24.

10. Kitahara M, Asano M, Naganawa H, Maeda K, Hamada M, Aoyagi T et al. Valilactone: An inhibitor of esterase, produced by actinomycetes. J Antibot 2012;40:1647-50.

11. Naveen BK. Production of Novel Lipase Inhibitor from Streptomyces Sp. Doctor of Philosophy, Thesis; 2005. p. 1-240.

12. Bayineni VK, Suresh S, Singh G, Kadeppagari RK. Development of a bioautographic method for the detection of lipase inhibitors. Biochem Biophys Res Commun 2014;453:784-6.

13. Weibel EK, Hadvary P, Hochuli E, Kupfer E, Lengsfeld H. Lipstatin, an inhibitor of pancreatic lipase, produced by Streptomyces toxytricini. I. Producing organism, fermentation, isolation and biological activity. J Antibiot (Tokyo) 1987;40:1081-5

14. Hochuli E, Kupfer E, Maurer R, Meister W, Mercadal Y, Schmidt K, et al. Lipstatin, an inhibitor of pancreatic lipase, produced by Streptomyces toxytricini. II. Chemistry and structure elucidation. J Antibiot (Tokyo) 1987;40:1086-91.

15. Shamsiya TK, Harohally NV, Manonmani HK. Production and purification of a new inhibitor of pancreatic lipase and hormone sensitive lipase from soil actinomycetes. Int J Inn Res Sci Eng Tech 2015;4:11600-9

16. Shaik M, Sankar GG, Iswarya M, Rajitha P. Isolation and characterization of bioactive metabolites producing marine Streptomyces parvulus strain sankarensis-A10. J Genet Eng Biotechnol 2017;15:87-94.

17. Funke G, Aravena-Roman M, Frodl R. First description of Curtobacterium spp. isolated from human clinical specimens. J Clin Microbiol 2005;43:1032-6 